\title{
Compatibility Analysis of Grid-connected Pico-hydro Systems using Conventional Photovoltaic Inverters
}

\author{
Vicente Leite $^{1,2}$, Ângela Ferreira ${ }^{1,2}$, José Couto ${ }^{1}$, José Batista ${ }^{1}$ \\ ${ }^{1}$ POLYTECHNIC INSTITUTE OF BRAGANÇA \\ Campus de Santa Apolónia \\ 5300-253 Bragança, Portugal \\ E-Mail: \{avtl, apf, jdvc,batista\}@ipb.pt \\ URL: http://www.ipb.pt \\ ${ }^{2}$ CISE - Electromechatronic Systems Research Centre \\ Covilhã, Portugal
}

\section{Keywords}

«Distributed power», «microgrid», «PV inverters», «renewable energy systems».

\begin{abstract}
Small scale hydropower has a considerable untapped potential, able to contribute to the increased energy demand. The integration of these systems into microgrids is an emerging solution for the electrification of remote areas and for self-sustainable power systems. This paper is devoted to the design optimization of grid-connected pico-hydro systems using conventional photovoltaic inverters, providing cost effective solutions able to explore a large amount of feasible sites. Experimental tests of the proposed innovative topology with two inverters and selected generators were performed, evaluating the performance in steady state and dynamic conditions, corroborate the proposed design procedure.
\end{abstract}

\section{Introduction}

There is an active seeking to increase the percentage share of the total electric energy supply from renewable and environmental friendly sources. Additionally, the integration of distributed generation (DG) into microgrids is an emerging solution for electrification of remote regions and also for selfsustainable systems. Small scale hydropower has an enormous untapped potential, which can make a significant contribution to the increasing energy demand, whilst decreasing the carbon footprint [1]. Small-scale hydropower stations are usually run-of-river schemes with no or shallow reservoirs, therefore associated with low impacts on the hydrological regime, on the aquatic or riparian ecosystems and on landscapes [2-4]. In order to enable the widespread exploitation of these systems in a cost effective way, it is necessary to develop a reliable and cheap conversion system, preferably based in mature technologies.

Pico-hydro power plants are very small-scale infrastructures designed to generate electric power, usually under $5 \mathrm{~kW}$ [5] by converting the power available in flowing waters in rivers, canals and streams and they are quite different from classical hydroelectric power plants. They are considered as the most appropriate solution for electrification of rural and isolated communities in hilly and mountainous regions where it is very expensive to implement conventional transmission and distribution power systems $[6,7]$. In fact, they have been particularly useful in some countries such as India, Nepal, China, Iran, Peru, Brazil and Kenya [8, 9].

Pico-hydro power plants are frequently used as stand-alone systems, providing electricity for basic needs of a house or a small village, with a turbine driving an AC generator and a design load to regulate the output voltage and frequency [7]. In these systems, since the energy is usually directly used by final consumers, it is essential to provide an effective regulation of the output voltage and frequency to prevent harming their appliances [2]. In some cases this is made by speed regulation using complex and high-inertia mechanical devices which adjusts the flow to the turbine to meet variations in power 
demand. In alternative, the rotational speed of the turbine is dictated by the available flow and a load management system regulates the power usage in order to balance the power input and output $[2,5]$. Some off-grid systems are based on a DC generator and a battery, with or without an off-grid inverter, depending on whether the loads are AC or DC $[10,11]$. When connected to a grid, conventional picohydro systems are designed to operate at very narrow speed range at different heads in order to approximate the rotational speed as close as possible to the rated speed of the generator [10], to ensure the requirements above mentioned. Most of the times, there will be a trade-off between head and flow rate.

Taking into account variability of heads and the water flow seasonal variation, the efficiency of picohydro power plants is greatly improved if they may work at variable speed, enabling increased energy capture [12]. Considering recent advances in low speed generators with off-the-shelf low power solutions for wind systems, e.g., variable speed pico-hydro systems can be applied beyond those conventional structures. If additionally, an inverter based grid interface is used, other turbine technologies become viable [13]. However, such dedicated inverters for grid connection as proposed recently $[12,14-16]$, would become an expensive solution and are far way to be an off-the-shelf technology available on the market. Conversely, photovoltaic (PV) inverters in the range of $5 \mathrm{~kW}$ are a mature and reliable technology widely available.

Therefore, and considering the limitations of conventional solutions, the procedure to integrate standard PV inverters in grid connected variable speed pico-hydro systems becomes attractive.

In this non-conventional solution, pico-hydro turbines are designed to behave electrically like PV strings, so that they interact effectively with conventional PV equipment, including grid connected inverters and charge controllers, as proposed by Smithies Technology Ldt. [17]. However, a complete description and investigation of a general approach is not available yet. For this purpose, a design procedure to integrate widespread standard PV inverters in grid connected variable speed pico-hydro systems, previously introduced in [18], is further investigated and optimized in this paper. In order to test the robustness of the integration, several experimental tests using different sets of generators and commercial inverters are reported.

Authors believe this innovative solution has a powerful application domain integrating pico-hydro power systems into microgrids in developing countries and in a huge number of applications in developed ones such as in household water supply [11], wastewater treatment facilities [19] and to improve control systems and optimize generation as a part of integrated water management systems $[1$, $20]$.

\section{Design procedure of grid-connected pico-hydro systems}

The proposed practical approach for grid-connected variable speed pico-hydro systems is illustrated by the design topology of Fig. 1. Instead of expensive turbines that allow an optimal control of the water flow, it is preferable to consider fixed-blade propeller water turbine, in order to reduce plant costs.

This solution relies in a permanent magnet (PM) synchronous generator and a PV inverter. The input voltage of the PV inverter is the rectified output voltage of the generator, by means of a power rectifier bridge.

The inverter decouples the generator output from the utility grid, which allows coupling the turbine directly to the generator for a wide range of head and flow combinations. The direct coupling of these two devices increases the efficiency and reliability of the overall system.

For proper operation and, above all, safety, the system requires an overvoltage protection circuitry, in order to prevent damaging the system' components, for instance, due to freewheeling if the electric grid fails.

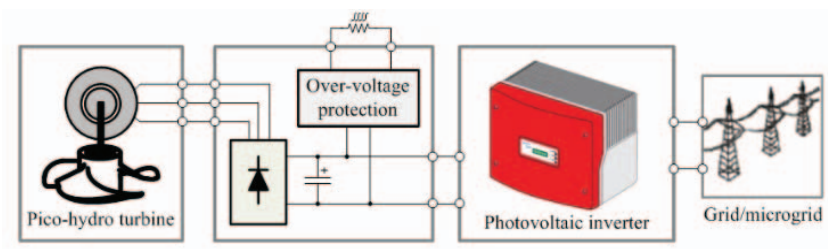

Fig. 1. Design topology for grid-connected pico-hydro systems. 
This simple approach has some important advantages such as high performance in terms of component reliability, broad range of products (up to $5 \mathrm{~kW}$ ) and technological independence. Furthermore, PV inverters are wide-spread, very cost competitive and their installation is widely disseminated among small and medium enterprises. Nevertheless, the integration of the inverter with the generator must be properly assured, as discussed hereinafter.

\section{Integration procedure of PV inverters with selected generators}

In order to be a reliable and safe solution, the integration of the inverter with the selected generator must be properly assured by combining the operating areas of both devices. In fact, the behaviour of the variable speed PM generator is very different from the one of a PV string. However, under certain operating conditions in terms of voltage and power ranges, the solution can be reliable and efficient, benefiting from the advantages previously mentioned.

The integration procedure is determined by the superposition of the operating areas of the inverter and the generator under analysis, as proposed in Fig. 2.

Regarding the PV inverter, the input voltage range is defined by $V_{D C \text { min }}$ and $V_{D C \text { max }}$; the range within it is able to track the maximum power point (MPP) is frequently defined by $V_{M P P \min } \geq V_{D C \min }$ and $V_{M P P_{\max }}<V_{D C \text { max }}$; the maximum input current and power of the inverter, $I_{D C \text { max }}$ and $P_{D C \text { max }}$ respectively, stablish the remaining limits of its operating area. An additional key characteristic of the inverter is the initial minimum input voltage needed for the inverter start working, $V_{P V \text { start }}$.

If a generator is to be connected to a conventional PV inverter, the operating point of the generator given by the output DC voltage and current, after rectification, i.e., the I-V characteristics, for the desired speed range, should be inside the safe operating area (SOA) of the inverter, as illustrated in Fig. 2 by straight lines. For a given speed, the I-V characteristic is defined by the no load rectified output voltage, $V_{G D C 0}$, and the slope given by the voltage drop in the internal impedance of the generator.

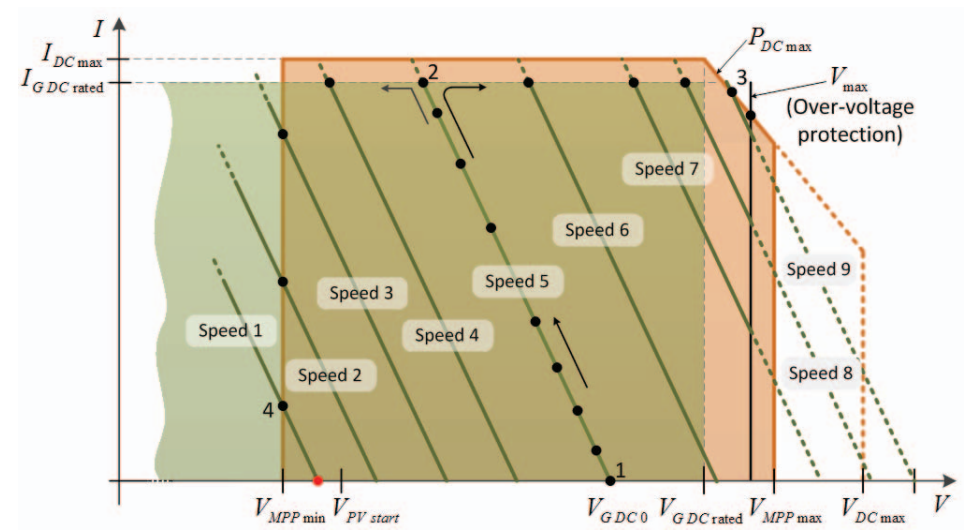

Fig. 2. Overlapping of the operating areas of PV inverter and generator.

The integration of the PM generator and the PV inverter as proposed is straightforward, provided that a set of conditions is guaranteed [18]:

- Taking into consideration the efficiency map of the inverter and the higher capacity factor of pico-hydro systems when compared with PV systems, the rated power of the generator should be in the range of $0.4 P_{D C \text { max }}$ to $P_{D C \text { max }}$ of the PV inverter;

- For the speed range of the application, the output DC voltage of the generator should be within the input voltage range of the PV inverter;

- The rated DC current of the generator must be equal or less the maximum input current of the $\mathrm{PV}$ inverter, and it is also recommended to be higher than $P_{D C} / V_{D C \text { min }}$, in order to assure the inverter is able to process the available power without overload the generator, i.e., $P_{D C} / V_{D C \text { min }} \leq I_{G D C \text { rated }} \leq I_{D C \text { max }}$ 
- The maximum voltage allowed by the over-voltage protection circuit should be lower than $V_{D C \max }$;

- The no-load output DC voltage of the generator for the initial speed must be higher than $V_{P V \text { start }}$;

- The system dynamics should be compliant with the tracking period of the MPP algorithm, to prevent the output DC voltage of the generator forsaking the operational voltage range during acceleration and deceleration periods [18].

Usually, it is possible to change parameters of conventional PV inverters such as maximum output power, initial minimum input voltage, MPP algorithm's tracking period, etc. These features may improve the robustness of the procedure presented above, by performing adjustments to a specific practical application, without losing its main benefit of the outlined plug-and-play procedure, as desired.

Taking into consideration the previous conditions, a possible route of the operating point of the generator, set by the MPP tracking algorithm of the inverter, is shown in Fig. 2 (black dots). For an initial speed higher than the corresponding to the initial minimum input voltage, "speed 5" e.g., the MPP algorithm will start from point 1 and increases the current up to its maximum (point 2). From this point, if the available power increases, the operating point will be set eventually in point 3 , provided that the corresponding voltage is lower than the maximum voltage allowed by the over-voltage protection. On the other hand, from point 2 , if the power decreases the operating point will be set in point 4 . It must be noticed that the maximum admissible current may be set by $I_{D C \text { max }}$ of the inverter, or through the internal impedance of the generator, from which the voltage drop superimposes an incremental current variation in finding the MPP. Usually, this situation occurs near the generator rated current, preventing critical overloads.

\section{Over-voltage protection}

The system requires an over-voltage protection, in order to protect the circuitry integrity against special states, such as sudden relieving of the inverter due to grid failure or grid synchronization, due to occurrences of low energy demand in stand-alone systems when the energy supply is high or when the hydro turbine starts (or restarts).

In order to the system be compliant with a cost effective, reliable and robust solution, the proposed overvoltage protection uses an electronic circuit which controls the power flow to an auxiliary power resistor to reduce the generator speed and thus the over-voltage in the event of surpassing a DC voltage limit. The protection circuit is shown in Fig. 3 and includes a voltage divider with a potentiometer $(\mathrm{P}=10 \mathrm{~K})$ to control the voltage level at which the IGBT will switch ON and when the dump load is connected to the DC-link to charge the generator.

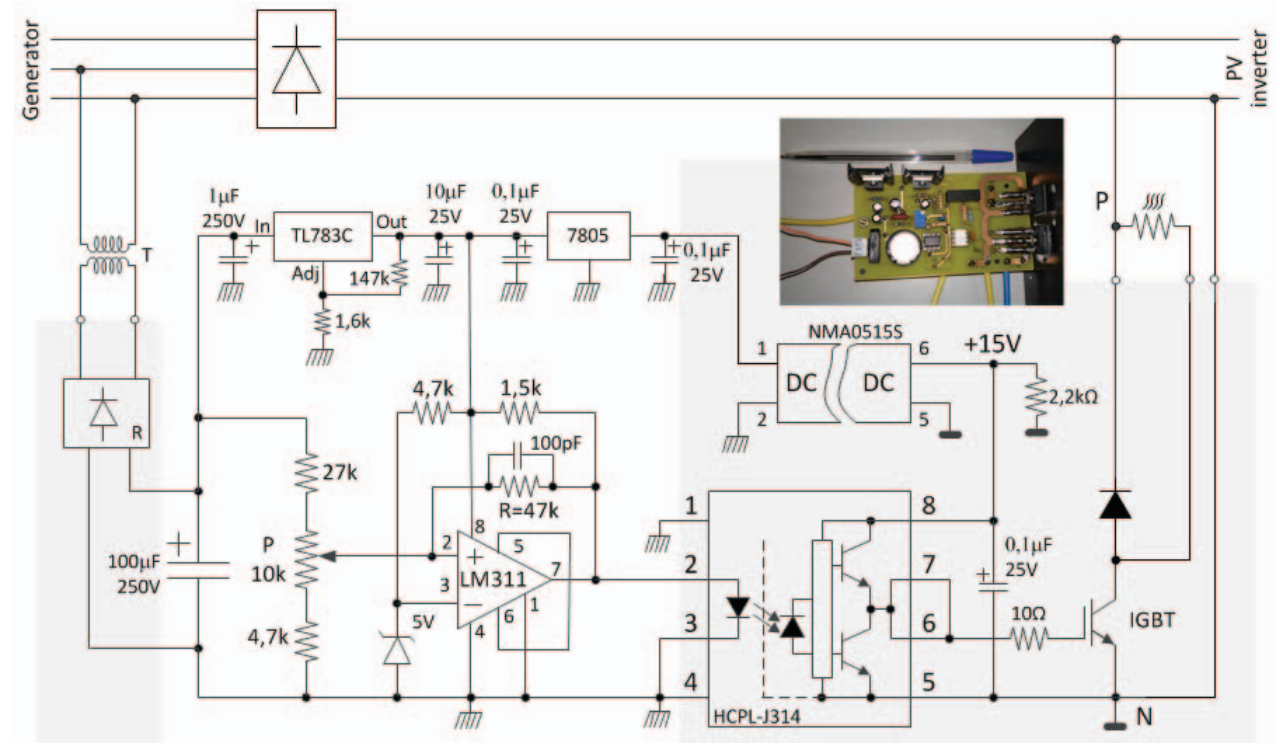

Fig. 3. Over-voltage protection circuit. 
The resistor $(\mathrm{R}=47 \mathrm{~K})$ controls the hysteresis window size of the comparator to define how far above the set point the DC-link voltage must be before the IGBT is turned ON and how far below the set point must be before turning OFF the IGBT.

Galvanic isolation is provide to the protection circuit. At the input side, a small transformer $(\mathrm{T})$ with a rectifier bridge is used. The advantage of using this transformer, instead of deriving a voltage divider directly from the DC-link, is that the control circuit can be the same for different voltage ranges of generators by choosing a suitable transformation ratio (400:55 in this case). At the output side, the galvanic isolation is provided by using the IGBT driver HCPL-314J together with an isolated DC-DC converter as power supply.

\section{Experimental analysis of the proposed design topology}

To validate the proposed design topology, the steady-state operation of the overall system has been tested with two standard PV inverters from SMA and selected PM synchronous generators. Additionally, several dynamic tests have also been performed in order to evaluate the performance of the over-voltage protection circuit.

There were used three different PM synchronous generators, two of them with reconfiguring windings in star and delta, which allow different characteristics. The technical data of the generators is presented in Table 1 and Table II introduces the main characteristics of the standard inverters under test.

Table I: Technical data of the PM synchronous generators

\begin{tabular}{|c|c|c|c|c|c|c|}
\hline \multirow{2}{*}{$\begin{array}{c}\text { Generator } \\
\text { (winding) }\end{array}$} & \multirow{2}{*}{$\mathrm{V} / \mathrm{rpm}$} & \multirow{2}{*}{$\mathrm{W} / \mathrm{rpm}$} & \multicolumn{4}{|c|}{ (1500 rpm } \\
\cline { 4 - 7 } & & $V_{D C 0}(\mathrm{~V})$ & $V_{D C}(\mathrm{~V})$ & $I_{D C}(\mathrm{~A})$ & $P_{D C}(\mathrm{~W})$ \\
\hline $\mathbf{1}$ & 0.15 & 0.86 & 219 & 150 & 8.6 & 1297 \\
\hline 2a (star) & 0.25 & 0.87 & 381 & 266 & 4.9 & 1300 \\
\hline 2b (delta) & 0.15 & 0.83 & 223 & 148 & 8.4 & 1245 \\
\hline 3a (star) & 0.4 & 0.53 & 594 & 440 & 1.8 & 796 \\
\hline 3b (delta) & 0.25 & 0.53 & 369 & 263 & 3 & 799 \\
\hline
\end{tabular}

Table II: Technical data of the inverters

\begin{tabular}{|c|c|c|c|c|c|c|}
\hline Inverter & $P_{D C \text { max }}(\mathrm{W})$ & $I_{D C \text { max }}(\mathrm{A})$ & $V_{D C \text { min }}(\mathrm{V})$ & $V_{D C \text { max }}(\mathrm{V})$ & $V_{M P P \text { range }}(\mathrm{V})$ & $V_{P V \text { start }}(\mathrm{V})$ \\
\hline SB 1500 & 1600 & 10 & 50 & 600 & $160-500$ & 80 \\
\hline SB 2100TL & 2200 & 11 & 125 & 600 & $125-480$ & 150 \\
\hline
\end{tabular}

\section{Turbine emulator system}

The static and dynamic behaviour of the micro-hydro system at laboratory level requires a prime mover emulator to assist the performance analysis of the overall system under variable conditions. The emulator relies on an inverter controlled squirrel cage induction motor of $3 \mathrm{~kW}$ rated power. Typically, hydro turbines present low dynamics speed variations due to high damping factor and inertia. Therefore, it is possible to consider the speed control of the electrical drive, as previously performed in [18]. Nevertheless, and keeping the focus of this work in the integration procedure of the PV inverter and the generator, to emulate flow variations or various head and flow combinations, it is adopted the power control of the drive which results in a variable speed operation, being the MPP algorithm of the inverter responsible for the efficiency and power management of the overall system, for grid-connected systems.

\section{Steady state operation}

The steady state operation of the overall system has been tested for several combinations of the two inverters with the selected generators. The results obtained are reported in Fig. 4 to 7. Generators 1 and 2 ( $\mathrm{a}$ and $\mathrm{b}$ ) have been tested with both PV inverters, while Generator 3 ( $\mathrm{a}$ and $\mathrm{b}$ ) has been tested with SB 2100TL, because it is not compatible with the SB 1500 inverter. In fact, taking into account the compatibility considerations previously introduced, specifically the one given by (1), the rated current of the generator, for both star and delta configurations, is lower than the ratio between the power range 
to be processed and the minimum input voltage of the inverter, which would easily overload the generator.

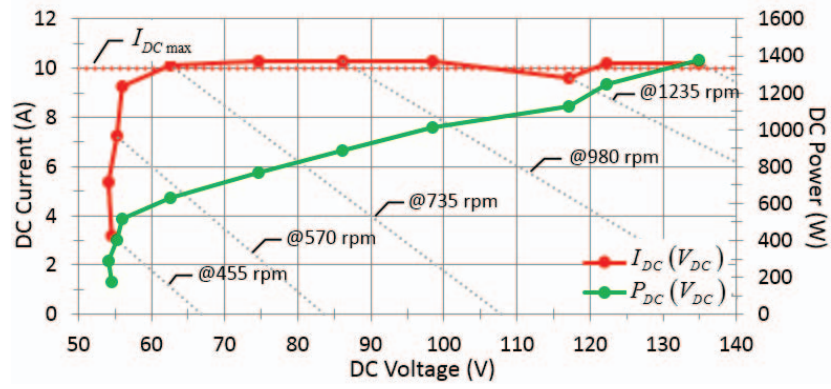

(a)

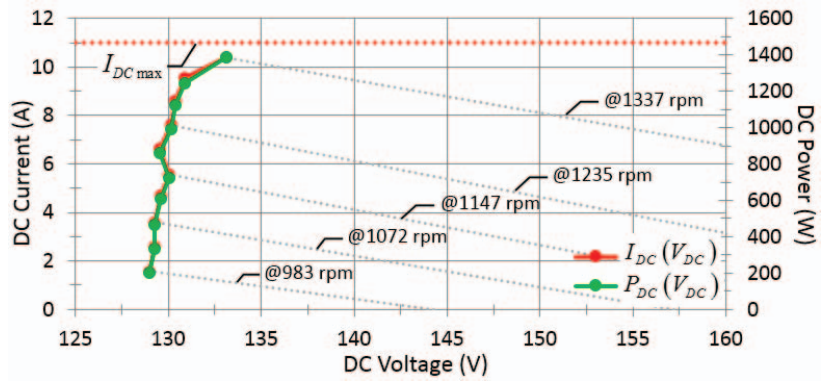

(b)

Fig. 4. Steady state operation of Generator 1with (a) SB1500 and (b) SB2100TL.

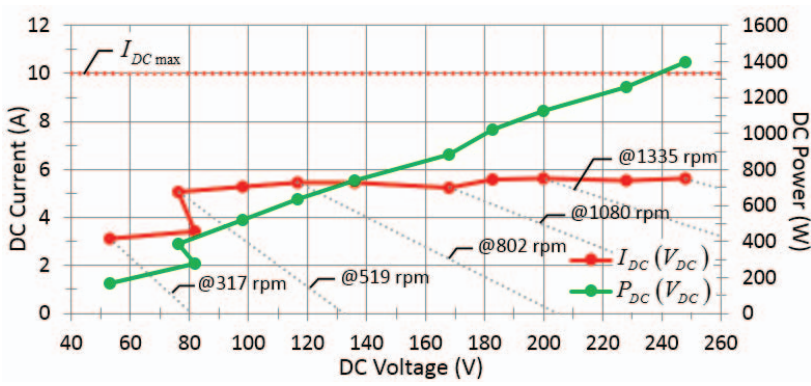

(a)

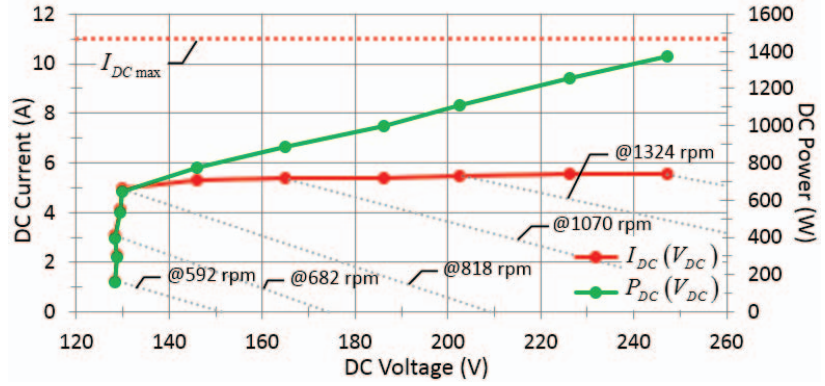

(b)

Fig. 5. Steady state operation of Generator 2a with (a) SB1500 and (b) SB2100TL.

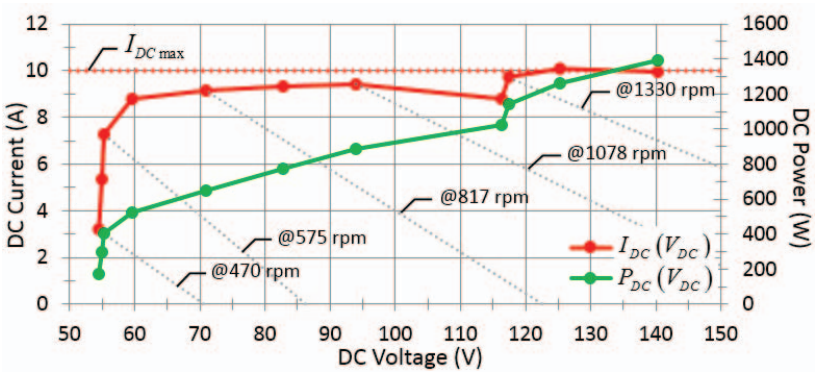

(a)

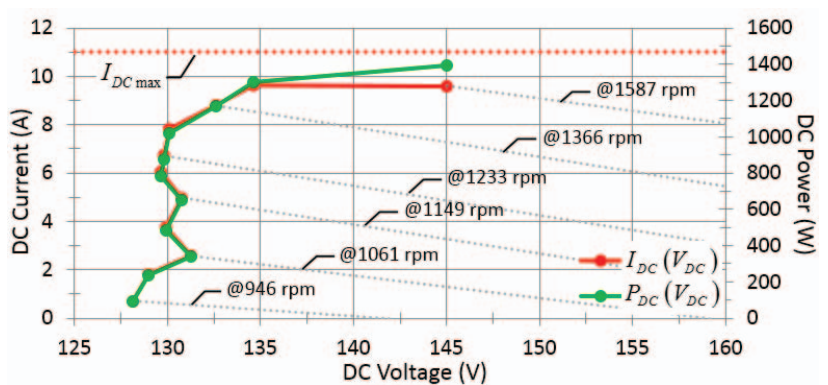

(b)

Fig. 6. Steady state operation of Generator 2b with (a) SB1500 and (b) SB2100TL.

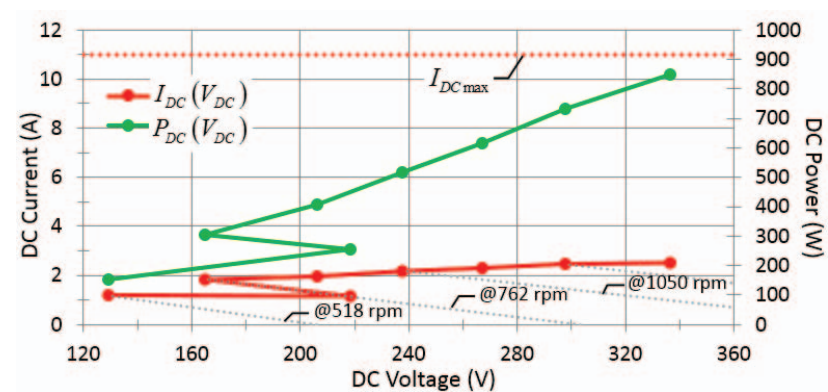

(a)

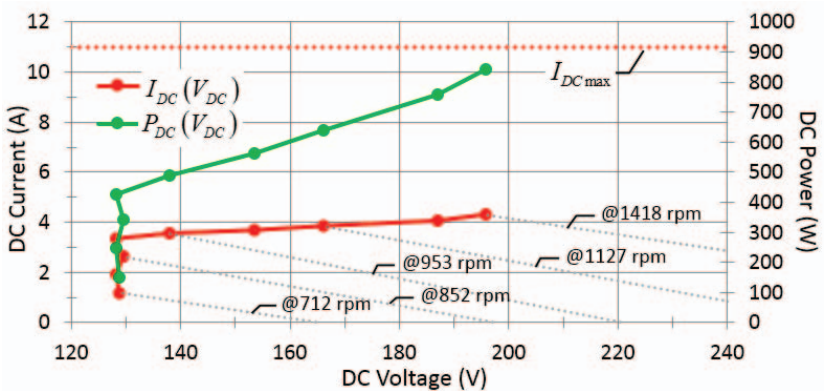

(b)

Fig. 7. Steady state operation of (a) Generator 3a and (b) Generator 3b with SB2100TL.

\section{Dynamic operation}

The main objective of the dynamic tests of the proposed structure is to evaluate the performance of the over-voltage protection circuit when the conversion power system is subjected to dynamic conditions. 
Tests have been performed monitoring the dissipated power in the auxiliary dump resistor of the overvoltage circuit, the voltage and current in the DC bus. These tests also allow the evaluation of the time delay till the inverter synchronization with the utility grid.

The experimental data acquisition set-up is based on the MATLAB with Simulink and the dSPACE 1103 controller board. The threshold of the maximum voltage allowed in the DC bus, set by the overvoltage protection circuit, is $180 \mathrm{~V}$ for the topology using Generator 1 and $250 \mathrm{~V}$ when using Generator $2 \mathrm{a}$.

Fig. 8 presents the synchronization with the utility grid and Fig. 9 reports a grid failure and the power flow diverted from the generator to the auxiliary power resistor by the over-voltage protection circuit, with the proposed topology using SB 1500 and SB 2100TL inverters and Generators 1 and 2a.
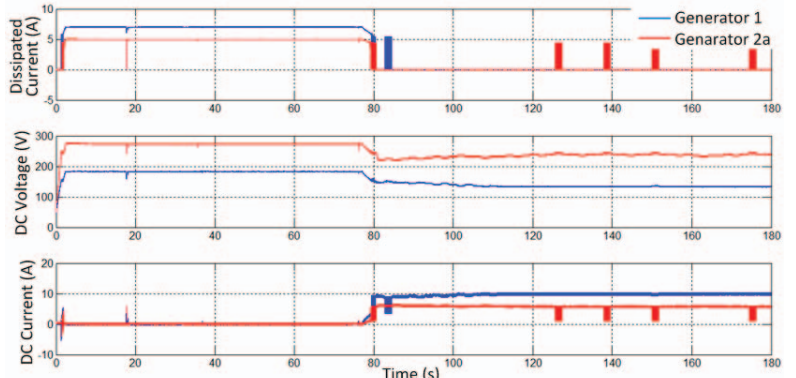

(a)
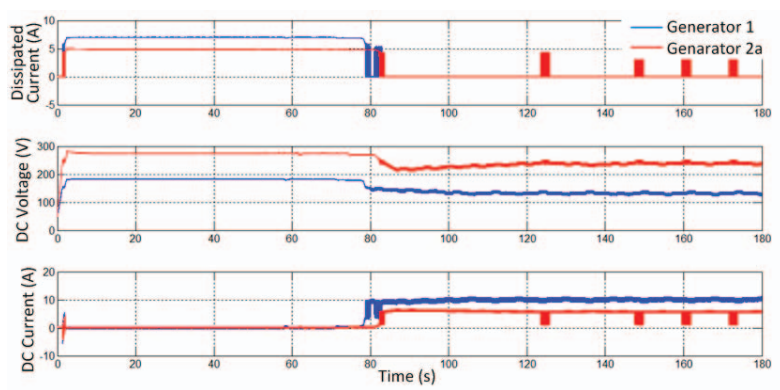

(b)

Fig. 8. Synchronization with the utility with (a) SB 1500 and (b) SB 2100TL inverters.
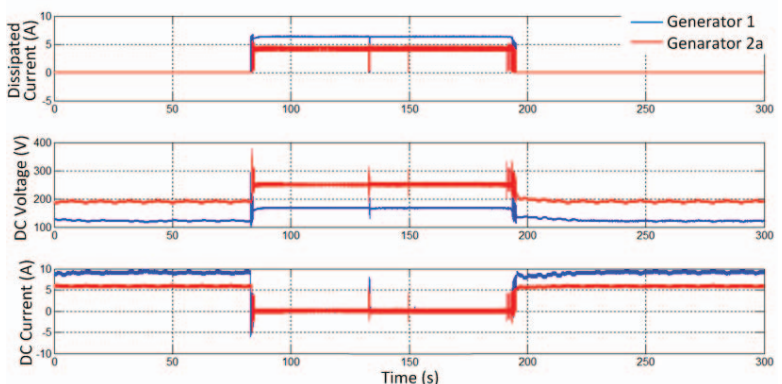

(a)
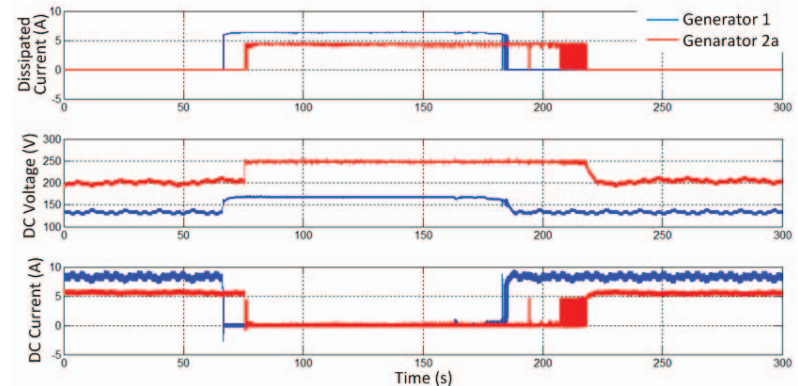

(b)

Fig. 9. Grid failure with (a) SB 1500 and (b) SB 2100TL inverters.

\section{Discussion}

From the obtained results for steady state performance and the analysis of the dynamic behaviour in specific conditions, it can been seen that the integration procedure of PV inverters with selected generators preconizes a stable and reliable configuration for grid-connected pico-hydro systems.

Regarding the steady state analysis, it can been seen that operating points of the generators are within the SOA of the inverters without surpassing their rated quantities in a critical extent, provided that the reference mechanical power is kept in the power range of the generators and the compatibility conditions are verified. For each tested generator, both inverters are able to process the available mechanical power, though with different I-V characteristics for each generator. Generators 1 to 3 work within the MPP range with SB 2100TL inverter (Fig. 4 (b), 5 (b), 6 (b) and 7), but when using SB 1500 inverter, the locus of the operating point is, in a large extent, out of its MPP range due to the deviation between its minimum input voltage and minimum MPP voltage (Fig. 4 (a), 5 (a) and 6 (a)).

It can been seen that for a given mechanical power reference, the inverter imposes an increasing current while keeping the voltage around its minimum input voltage till reaching its maximum DC input current or while the ratio between the processed power and the minimum input DC voltage is lower than the rated current of the generator. For instance, Generators 1 and $2 \mathrm{~b}$ have rated currents of $8.6 \mathrm{~A}$ and $8.4 \mathrm{~A}$, respectively. While $P_{D C} / V_{D C \text { min }}$ is lower than those quantities, for an increasing input power both inverters increase the current till this increment is overlapped by the voltage drop in the internal impedance of the generators for a given power to be processed. From this point forward, inverters 
increase the voltage, while keeping the current, approximately, in its previous maximum. Eventually, inverters may increase a little further the current (e.g., Fig. 6 (a)) overloading the generators in an acceptable extent.

This behavior is further corroborated with Generator 2a (Fig.5) and Generators 3a and 3b (Fig. 7), which have rated currents considerably lower than the maximum DC input currents of the inverters and, again, not being surpassed in the power range of the application.

From the reported results in the dynamic analysis it can be seen that the time delay for the inverter synchronization with the grid is 80 seconds for both inverters (Fig. 8), being a parametrized value by manufacturers. After the synchronization, it can be seen that the topology using Generator 2 (a) is operating with a DC voltage near the threshold of the maximum DC voltage allowed by the protection circuit which leads to current divert to the auxiliary power resistor for short time intervals, restoring the DC voltage below its maximum allowed. Fig. 9 validates the instantaneous limitation of the DC voltage, when the grid fails, with the proposed topology using both inverters.

\section{Conclusion}

This paper presents a practical approach for grid-connected pico-hydro systems using conventional photovoltaic inverters, preconizing a cheap solution with off-the-shelf technology. For this purpose, a design topology and procedure were presented to integrate pico-hydro generators into the grid using conventional PV inverters. This topology allows a variable speed operation mode whereas a maximum power efficiency operation tracking is provided by the PV inverter. An over-voltage protection circuit was designed in order to protect both the generator and inverter against special states, such as sudden relieving of the inverter due to grid failure. Steady state and dynamic performances of the proposed approach have been experimentally tested under power control by using a turbine emulation system. The results obtained allow the validation of the proposed design procedure as well as the definition of the operating conditions, particularly in applications with a wide speed range.

\section{References}

[1] European Commission. (-, Access Date: September, 2015). Hydro Energy, Technical background. Available: http://ec.europa.eu/research/energy/eu/index_en.cfm?pg=research-hydropower

[2] V. Leite, T. Figueiredo, T. Pinheiro, A. Ferreira and J. Batista, "Dealing with the Very Small: First Steps of a Picohydro Demonstration Project in an University Campus", in Proc. International Conference on Renewable Energies and Power Quality (ICREPQ'12), Santiago de Compostela, Spain, 2012.

[3] European Commission. (-, Access Date: September, 2015). Hydropower. Available: http://ec.europa.eu/research/energy/eu/index_en.cfm?pg=research-hydropower

[4] European Commission, "A Guide to Environmental Impact Assessment of Small Hydropower Plants", Directorate-General for Energy and Transport, Brussels, 2000, p. 110.

[5] O. Paish, "Small Hydro Power: Technology and Current Status", Renewable and Sustainable Energy Reviews, vol. 6, (6), pp. 537-556, 2002.

[6] A. Desai, I. Mukhopadhyay and A. Ray, "Theoretical Analysis of a Pico-hydro Power System for Energy Generation in Rural or Isolated Area", in Proc. IEEE PES Asia-Pacific Power and Energy Engineering Conference, APPEEC 2014, Brisbane, 2014, pp. 1-4.

[7] S. J. Williamson, A. Griffo, B. H. Stark and J. D. Booker, "Control of parallel single-phase inverters in a lowhead pico-hydro off-grid network", in Proc. 39th Annual Conference of the IEEE Industrial Electronics Society, IECON 2013 2013, pp. 1571-1576.

[8] S. Khurana and A. Kumar, "Small Hydro Power - A review", International Journal of Engineering, Science and Metallurgy, vol. 1, (2), pp. 278-282, 2011.

[9] D. A. Howey, "Axial Flux Permanent Magnet Generators for Pico-Hydropower", in Proc. EWB-UK Research Conference, 2009.

[10] A. M. A. Haidar, M. F.M. Senan, A. Noman and T. Radman, "Utilization of Pico Hydro Generation in Domestic and Commercial Loads", Renewable and Sustainable Energy Reviews, vol. 16, (1), pp. 518-524, Jan. 2012. 
[11] G. Yadav and A. K. Chauhan, "Design and Development of Pico Micro Hydro System by Using House Hold Water Supply", International Journal of Research in Engineering and Technology, vol. 3, (10), pp. 114-119, June 2014.

[12] W. Mazgaj, Z. Szular, T. Węgiel and T. Sobczyk, "Small Hydropower Plant with Variable Speed PM Generator", Przegląd Elektrotechniczny, vol. 87, (5), pp. 282-287, 2011.

[13] S. J. Williamson, B. H. Stark and J. D. Booker, "Low Head Pico Hydro Turbine Selection using a MultiCriteria Analysis", Renewable Energy, vol. 61, pp. 43-50, Jan. 2014.

[14] M. G. Molina and M. Pacas, "Improved Power Conditioning System of Microhydro Power Plant for Distributed Generation Applications", in Proc. International Conference on Industrial Technology, ICIT 2010, Vi a del Mar, 2010, pp. 1733-1738.

[15] A. Roque, D. M. Sousa, C. Casimiro and E. Margato, "Technical and Economic Analysis of a Microhydro Plant - a Case Study", in Proc. 7th International Conference on the European Energy Market, EEM 2010, 2010, pp. 1-6.

[16] U. C. Rathore and S. Singh, "Power Quality Control of SEIG based Isolated Pico Hydro Power Plant Feeding Non-Linear Load", in Proc. 6th India International Conference on Power Electronics, IICPE 2014, 2014, pp. 15 .

[17] Andrew Smithies, "PowerSpout GE and ME Design for Compatibility with Inverters and MPPT Charge Controllers", Available: http://powerspout.com/assets/Published/public/PLT/PLT-Compatibility/2011-01PowerSpout-PV-compatibility-3-Nov-2011.pdf, Nov., 2011, p. 28.

[18] A. V. Leite, J. Couto, A. Ferreira and J. Batista, "A Practical Approach for Grid-connected Pico-hydro Systems using Conventional Photovoltaic Inverters", in Proc. IEEE International Energy Conference, ENERGYCON 2016, Leuven, Belgium, 2016.

[19] T. Gaius-Obaseki, "Hydropower Opportunities in the Water Industry", International Journal of Environmental Sciences, vol. 1, (3), pp. 392-402, 2010.

[20] H. Zainuddin, M. S. Yahaya, J. M. Lazi, M. F. M. Basar and H. Ibrahim, "Design and Development of Picohydro Generation System for Energy Storage Using Consuming Water Distributed to Houses", International Journal of Electrical, Computer, Energetic, Electronic and Communication Engineering, World Academy of Science, Engineering and Technology, vol. 3, (11), pp. 1928-1933, 2009. 